\title{
Regional parafoveal vessel density changes in diabetic patients without retinopathy
}

\author{
Sheyla L. Escobar-Villado and Virgilio Lima-Gómez* \\ ${ }^{1}$ School of Medicine, Universidad Autónoma de Ciudad Juárez, Chihuahua; ${ }^{2}$ Ophthalmology Department, Hospital Juárez de México, Mexico City, \\ Mexico
}

\begin{abstract}
Introduction: Regional parafoveal vessel density changes have not been characterized in patients with type 2 diabetes without retinopathy. Objective: To compare regional changes in vessel density between subjects without diabetes (group 1) and with diabetes without retinopathy (group 2). Methods: Observacional, retrospective, cross-sectional, comparative study. Parafoveal vessel density by quadrants was compared between groups and between quadrants in each group; density of each quadrant and inner density were correlated, as well as the contribution of each quadrant to inner density (linear regression). Results: Thirty-four eyes were analyzed in group 1 and 38 in group 2; in the latter, inner vessel density (20.75 vs. 21.85, $p=0.021)$ and that of superior quadrants (21.05 vs. 21.75, $p<0.001)$, and nasal quadrants (20.95 vs. 21.50, $p=0.023$ ) were lower. In the regression analysis, superior and nasal quadrants had the largest contribution to the change in inner vessel density in group 2 $(\beta=0.361$ and $\beta=0.294$, respectively). Conclusions: Parafoveal inner vessel density decreases in diabetic patients without retinopathy at the expense of superior and nasal quadrants, which indicates that further evaluation is required for early microvascular disease to be detected.
\end{abstract}

KEY WORDS: Parafoveal vessel density. Type 2 diabetes. Diabetic retinopathy. Optical coherence tomography angiography.

\section{Cambios regionales de densidad vascular parafoveal en pacientes diabéticos sin retinopatía}

\section{Resumen}

Introducción: Los cambios regionales de densidad vascular parafoveal no han sido caracterizados en los pacientes con diabetes tipo 2 sin retinopatía. Objetivo: Comparar los cambios regionales de densidad vascular entre sujetos sin diabetes (grupo 1) y con diabetes sin retinopatía (grupo 2). Métodos: Estudio observacional, retrospectivo, transversal y comparativo. La densidad vascular parafoveal por cuadrantes se comparó entre grupos y entre cuadrantes en cada grupo; se correlacionó la densidad de cada cuadrante y la densidad interna, así como la contribución de cada cuadrante a la densidad interna (regresión lineal). Resultados: Se analizaron 34 ojos en el grupo 1 y 38 en el grupo 2; en este fue menor la densidad vascular interna (20.75 versus 21.85, $p=0.021$ ) y la de los cuadrantes superior $(21.05$ versus $21.75, p<0.001)$ y nasal (20.95 versus 21.50, $p=0.023$ ). En el análisis de regresión, los cuadrantes superior y nasal tuvieron la mayor contribución al cambio en la densidad vascular interna $(\beta=0.361, \beta=0.294)$ en el grupo 2. Conclusiones: La densidad vascular interna parafoveal disminuye en los pacientes diabéticos sin retinopatía, a expensas de los cuadrantes superior y nasal, por lo que se requiere evaluación adicional para detectar afecciones microvasculares tempranas.

PALABRAS CLAVE: Densidad vascular parafoveal. Diabetes tipo 2. Retinopatía diabética. Angiografía por tomografía de coherencia óptica.

Correspondence:

*Virgilio Lima-Gómez

E-mail: forscher7@gmail.com
Gac Med Mex. 2021;157:338-342

Contents available at PubMed

www.gacetamedicademexico.com

0016-3813/@ 2021 Academia Nacional de Medicina de México, A.C.. Published by Permanyer. This is an open access article under the CC BY-NC-ND license (http://creativecommons.org/licenses/by-nc-nd/4.0/). 


\section{Introduction}

Diabetic retinopathy (DR) is the leading cause of blindness at working age worldwide. The risk of visual loss in people with diabetes is $25 \%$ higher than in people without it ${ }^{1}$. Hyperglycemia plays an important role in the pathogenesis of microvascular damage to the retina; the first responses of these blood vessels to hyperglycemia are dilatation and flow changes ${ }^{2}$.

Until recently, the diagnosis of retinal damage caused by diabetes was limited to ophthalmoscopy, fundus photography, and fluorescein angiography ${ }^{3}$. Optical coherence tomography angiography (OCT-A) is a recently-developed technology that detects the movement of erythrocytes and allows retinal microvasculature delimitation, with a resolution that is comparable to that of a histological section, which is why it constitutes a non-invasive alternative for investigating $D^{4,5}$.

The OCT-A equipment Cirrus $5000^{\mathrm{TM}}$ with Angioplex ${ }^{\mathrm{TM}}$ (Zeiss, Meditec, Dublin, CA) can generate a $3 \times 3-\mathrm{mm}$ map and measure vessel density at the macular central region, which is the area with best vision. This equipment automatically determines superficial capillary plexus vessel density at the central area (a 1-mm central circle) and in a ring $1 \mathrm{~mm}$ away from it; it also measures full density of the central $3 \mathrm{~mm}$ and can divide the ring into quadrants: upper, temporal, lower, and nasal, for each one of which it records vessel density ${ }^{6}$.

A reduction in parafoveal vessel density on superficial and deep plexus has been identified in diabetic patients with no clinical evidence of diabetic retinopathy ${ }^{7}$, which is accentuated as the duration of diabetes increases $^{8}$. However, it is unknown how vessel density regional reductions contribute to it and if any is more marked, which could indicate anticipated selective damage. A study was designed to compare parafoveal vessel density regional changes between subjects without diabetes and patients with diabetes without retinopathy in order to determine if there are sectors with more damage, where earlier detection could be made.

\section{Methods}

An observational retrospective, cross-sectional, comparative study was carried out. Target population were subjects without diabetes and patients with type 2 diabetes without diabetic retinopathy from Mexico City and its metropolitan area. Accessible population were patients treated at the ophthalmology department of a federal referral hospital. The study was carried out from July 3 to August 3, 2020, adhered to the principles of the Declaration of Helsinki and received authorization from the research and research ethics committees of the hospital where it was developed.

Subjects without diabetes and patients with type 2 diabetes without DR, of either gender, aged 30-70 years, with any degree of corrected visual acuity, and who had an OCT-A map of adequate quality were included. Patients with any other type of retinal disease or ocular media opacities were excluded. Patients with retinal thickness values outside \pm 3 standard deviations were eliminated.

The sample was divided in two groups: 1 , without diabetes and 2, with diabetes without DR. Only one eye was included per subject, which was randomly selected among the patients who met the selection criteria.

OCT-A images were obtained with the Cirrus 5000 $\mathrm{HD}$ w/Angioplex equipment. The characteristics of the scans were high-resolution 6-mm macular cube and $3 \times 3-\mathrm{mm}$ superficial capillary plexus angiogram, which were acquired using the equipment's automatic segmentation algorithm; image quality controls included correct centering on the fovea, absence of flicker or movement artifacts, and a signal intensity $>7$.

The study variable was superficial plexus parafoveal vessel density $\left(\mathrm{mm}^{-1}\right)$, which was measured, by regions (central, inner, and full); inner density was measured by quadrants: upper, lower, temporal, and nasal. Secondary variables were retinal thickness (in $\mu \mathrm{m}$ ) and macular volume (in $\mathrm{mm}^{3}$ ). All measurements were automatically calculated by the equipment.

Numerical variables were reported as the median and interquartile range. Parafoveal vessel density was compared between groups using Mann-Whitney's U-test; vessel density was compared between quadrants in each group using Kruskal-Wallis test. At each group, the correlation between each quadrant densities and inner density was identified using Spearman's rho test. A multivariate analysis was carried out using linear regression to determine the contribution of each quadrant density to inner density distribution; the percentile of the group without diabetes was identified, in which the $90^{\text {th }}$ percentile of the group with diabetes was found for the quadrants with the largest contribution to changes in inner density. The information was stored and analyzed in version 22 of the Statistical Package for the Social Sciences (SPSS) program for Windows; a p-value $<0.05$ was considered to be significant. 
Table 1. Comparison of baseline variables between groups (median and interquartile range)

\begin{tabular}{|c|c|c|c|}
\hline Variables & Group $1(n=34)$ & Group $2(n=38)$ & p \\
\hline Age (years) & $46(33.75-60.50)$ & $56(49.7-60.5)$ & $0.005^{*}$ \\
\hline $\begin{array}{l}\text { Central field } \\
\text { thickness }(\mu \mathrm{m})\end{array}$ & $250(237.50-268)$ & $250.50(232-265.5)$ & $0.513^{*}$ \\
\hline $\begin{array}{l}\text { Macular volume } \\
\left(\mathrm{mm}^{3}\right)\end{array}$ & $10.10(9.87-10.52)$ & $9.90(9.70-10.30)$ & $0.222^{*}$ \\
\hline $\begin{array}{l}\text { Female gender } \\
(\%)\end{array}$ & 52.9 & 63.2 & $0.380^{* \star}$ \\
\hline $\begin{array}{l}\text { Hypertension } \\
(\%)\end{array}$ & 0 & 35.7 & $0.291^{* *}$ \\
\hline
\end{tabular}

Table 2. Vessel densities regional comparison between groups (median and interquartile range)

\begin{tabular}{|l|c|c|c|}
\hline $\begin{array}{l}\text { Vessel } \\
\text { density }\end{array}$ & Group $1(\mathbf{n}=34)$ & Group $2(\mathbf{n}=38)$ & $p^{*}$ \\
\hline Central & $10.90(7.70-12.42)$ & $8.55(6.87-11.65)$ & 0.066 \\
\hline Inner & $21.85(20.27-23.02)$ & $20.75(19.47-21.70)$ & 0.021 \\
\hline Full & $20.45(18.97-21.90)$ & $19.55(18.05-20.42)$ & 0.029 \\
\hline Upper & $21.75(20.40-23.07)$ & $21.05(19.60-21.87)$ & $<0.001$ \\
\hline Temporal & $21.95(20.10-22.90)$ & $21.50(19.80-22.02)$ & 0.177 \\
\hline Lower & $21.40(20.30-23.02)$ & $21.05(19.50-22.40)$ & 0.160 \\
\hline Nasal & $21.50(20.57-23.52)$ & $20.95(19.75-21.72)$ & 0.023 \\
\hline
\end{tabular}

Table 3. Correlation between vessel density and inner density by quadrant and group

\begin{tabular}{l|c|c|c|c|}
\hline \multirow{2}{*}{ Quadrant } & \multicolumn{2}{|c|}{ Group 1 } & \multicolumn{2}{c|}{ Group 2 } \\
\cline { 2 - 5 } & Rho* & $p$ & Rho* & P \\
\hline Upper & 0.249 & $<0.001$ & 0.361 & $<0.001$ \\
\hline Temporal & 0.312 & $<0.001$ & 0.272 & $<0.001$ \\
\hline Lower & 0.237 & $<0.001$ & 0.285 & $<0.001$ \\
\hline Nasal & 0.286 & $<0.001$ & 0.294 & $<0.001$ \\
\hline *Spearman's rho test. & & & &
\end{tabular}

\section{Results}

Seventy-two patients aged 20 to 77 years $(54.5$, 43-60) were evaluated; 42 were females (58.3\%); 34

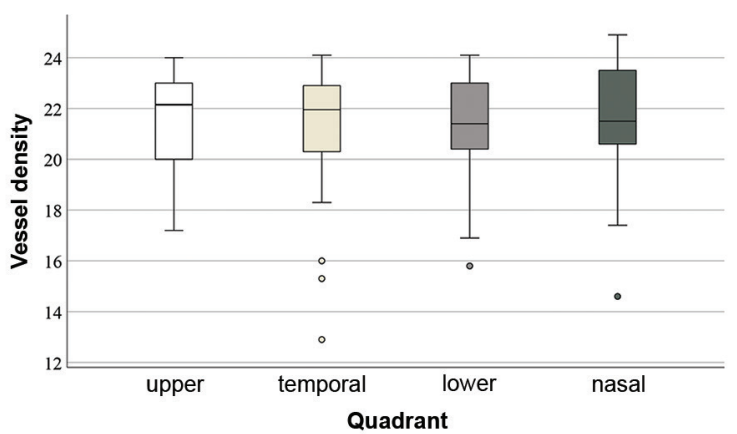

Figure 1. Vessel density comparison between quadrants in group $1(n=34)$. Vessel density in $\mathrm{mm}^{-1}$.

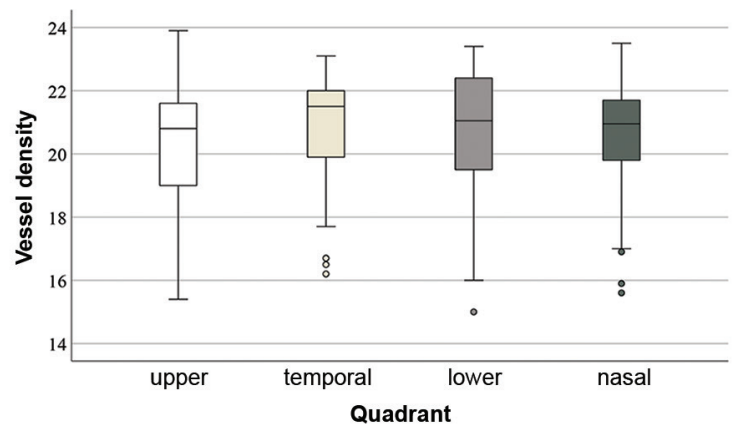

Figure 2. Vessel density comparison between quadrants in group 2 $(n=38)$. Vessel density in $\mathrm{mm}^{-1}$.

did not have diabetes, and 38 did. Diabetes evolution time ranged from 1 to 18 years $(5,2-12) ; 10$ patients (13.8\%) suffered from systemic arterial hypertension. The comparison of baseline variables between groups is presented in table 1.

The comparison of vessel density between groups is shown in table 2; in group 2, inner, full, upper and nasal densities were lower than in group 1. The comparison of vessel density between quadrants did not show any statistical difference in group 1 (Fig. 1, $p=0.698$ ) or in group 2 (Fig. 2, $p=0.595$ ).

Table 3 shows the correlation between vessel density and inner density per quadrant and per group. The linear regression analysis identified that, in group $1(n=34)$, the quadrants with the highest contribution to inner density were the temporal $(\beta=0.312, p<0.001)$ and the nasal quadrant $(\beta=0.286, p<0.001)$. In Group $2(n=38)$, the quadrants that the most contributed to inner density were the upper $(\beta=0.361, p<0.001)$ and the nasal quadrant $(\beta=0.294, p<0.001)$, which had lower vessel density than the same quadrants in group 1 . 
Table 4. Parafoveal vessel density percentiles by quadrants and groups

\begin{tabular}{|l|l|l|l|l|l|l|l|l|l|}
\hline Quadrant & \multicolumn{2}{|c|}{ Upper } & \multicolumn{3}{c|}{ Nasal } & \multicolumn{2}{c|}{ Tower } \\
\hline Percentile & Group 1 & Group 2 & Group 1 & Group 2 & Group 1 & Group 2 & Group 1 & Group 2 \\
\hline 90 & 23.63 & 22.77 & 24.20 & 22.85 & 23.55 & 22.51 & 23.40 & 22.82 \\
\hline 80 & 23.30 & 22.20 & 23.60 & 21.84 & 23.10 & 22.40 & 23.00 & 22.26 \\
\hline 75 & 23.07 & 21.87 & 23.52 & 21.72 & 23.02 & 22.40 & 22.90 & 22.02 \\
\hline 70 & 22.90 & 21.70 & 23.45 & 21.63 & 22.75 & 21.92 & 22.70 & 21.90 \\
\hline 60 & 22.50 & 21.48 & 22.90 & 21.44 & 22.00 & 21.34 & 22.60 & 21.60 \\
\hline 50 & 21.75 & 21.05 & 21.50 & 20.95 & 21.40 & 21.05 & 21.95 & 21.50 \\
\hline 40 & 21.10 & 20.62 & 21.10 & 20.68 & 21.00 & 20.52 & 20.90 & 21.22 \\
\hline 25 & 20.40 & 19.60 & 20.57 & 19.75 & 20.30 & 19.50 & 20.10 & 19.80 \\
\hline
\end{tabular}

In the distribution analysis, group $290^{\text {th }}$ percentile values were found to correspond to group $160^{\text {th }}$ and $50^{\text {th }}$ percentiles at upper and nasal quadrants. In addition, group $290^{\text {th }}$ percentile values corresponded to group $160^{\text {th }}$ and $70^{\text {th }}$ percentiles at the lower and temporal quadrants (Table 4).

\section{Discussion}

In subjects without diabetes, the largest contribution to inner parafoveal vessel density distribution was by the temporal and nasal quadrants. However, in diabetic patients without retinopathy, the quadrants that the most contributed were the upper and nasal quadrants, whose vessel density was statistically lower than that of group 1.

A study in patients from China evaluated the contribution of vessel density per quadrant for developing diabetic retinopathy; for this, patients without retinopathy were compared with patients with retinopathy of different degrees. This study used different equipment from that of the present investigation, it did not report vessel density values by quadrant and neither did it compare these values with those of subjects without diabetes ${ }^{9}$.

Van de Kreeke et al. reported changes in retinal layers and presence of DR over time; they compared patients without retinopathy and patients with mild retinopathy; they found changes in retinal thickness, which were more noticeable at the temporal sector. This study reported retinal layer values by quadrants, but did not compare these values or vessel density with those of subjects without diabetes ${ }^{10}$; however, it demonstrated regional longitudinal variations, mainly at sites where DR was developing.

Uğurlu had also described a reduction in vessel density by quadrants between diabetic patients with and without retinopathy, but did not compare his data with the values of subjects without diabetes, and neither did he determine regional contribution to global change ${ }^{11}$. AttaAllah identified a reduction in vessel density at upper and lower sectors in diabetic patients without edema in comparison with subjects without diabetes; however, patients with diabetes had moderate or severe non-proliferative $\mathrm{DR}^{12}$.

The comparison of vessel density between quadrants failed to show statistical differences within each group, but inner density decreased in group 2 . In that group, there was no asymmetry between quadrants that would allow identifying the most affected, given that, in all, there was a reduction that was only statistically significant in two, but it was enough to decrease inner vessel density.

In our study, the quadrants that had a statistical reduction in vessel density were the ones that most contributed to inner density changes; the comparison of percentiles between groups showed that the difference was not minimal, which suggests that microvascular damage at these quadrants was not recent. It would be convenient to search for patients with earlier damage in order to identify whether the effect is consistent in those quadrants that had vessel density reduction.

Waiting for inner density to decrease could delay microvascular damage diagnosis, particularly when comparing retinal capillaries involvement with that of other organs' vascular plexuses is sought ${ }^{13,14}$. 
The strengths of the study were parameters automatic quantification, inter-observer variability elimination, and signal intensity $>7$. One limitation was that only the superficial plexus density was analyzed, not that of deep plexus, since the equipment only automatically measures the former. Another limitation was that, although in group 2, patients diabetes evolution time had a median of 5 years, $35.7 \%$ had hypertension. It will be necessary to weigh the contribution of this disease to the development of retinal capillary loss.

In the future, longitudinal studies should be performed to characterize in detail the impact of early microvascular damage to the macula before the onset of diabetic retinopathy. Regional evaluation by quadrants could be an alternative for early detecting and addressing retinal microangiopathy caused by diabetes.

\section{Conclusion}

A reduction in parafoveal inner vessel density was found in diabetic patients without retinopathy, mainly at the expense of a decrease at upper and nasal quadrants. This finding suggests localized damage with a longer duration, which should be confirmed in order to detect earlier microvascular compromise.

\section{Acknowledgments}

To Zeiss, Mexico, for the support for the evaluation of patients with the Cirrus 5000 w/Angioplex equipment.

\section{Funding}

The authors did not receive any sponsoring to carry out this article.

\section{Conflict of interests}

The authors declare that they had no conflicts of interest relevant to the development or publication of the work.

\section{Ethical disclosures}

Protection of human and animal subjects: The authors declare that no experiments were performed on humans or animals for this research.

Confidentiality of data: The authors declare that they followed the protocols of their work center on the publication of patient data.

Right to privacy and informed consent: The authors declare that no patient data appear in this article.

\section{References}

1. Zheng $Y$, He M, Congdon N. The worldwide epidemic of diabetic retinopathy. Indian J Ophthalmol. 2012;60:428-31.

2. Wang W, Lo A. Diabetic retinopathy: pathophysiology and treatments. Int J Mol Sci. 2018;19:1816.

3. Lee J, Rosen R. Optical coherence tomography angiography in diabetes. Curr Diab Rep. 2016;16:123.

4. Gildea D. The diagnostic value of optical coherence tomography angiography in diabetic retinopathy: a systematic review. Int Ophthalmol. 2018;39:2413-33.

5. Batista M, Borrlli E, Sacconi R, Bandello F, Querques G. Optical coherence tomography angiography in diabetes: a review. Eur J Ophthalmol. 2020;30:411-6.

6. Rosenfeld P, Durbin M, Roisman L, Zheng F, Miller A, Robbins G, et al. ZEISS Angioplex ${ }^{\mathrm{TM}}$ spectral domain optical coherence tomography angiography: technical aspects. Dev Ophthalmol. 2016;56:18-29.

7. Cao D, Yang D, Huang Z, Zeng Y, Wang J, Hu Y, et al. Optical coherence tomography angiography discerns preclinical diabetic retinopathy in eyes with Type 2 diabetes without clinical diabetic retinopathy. Acta Diabetol. 2018;55:469-77.

8. Lee MW, Lee WH, Ryu CK, Kim TY, Lim HB, Lee YH, et al. Effects of prolonged Type 2 diabetes on the inner retinal layer and macular microvasculature: an optical coherence tomography angiography study. J Clin Med. 2020;9:1849.

9. Xie N, Tan Y, Liu S, Xie Y, Shuai S, Wang W, et al. Macular vessel density in diabetes and diabetic retinopathy with swept-source optical coherence tomography angiography. Graefes Arch Clin Exp Ophthalmol. 2020;258:2671-9.

10. Van de Kreeke J, Darma S, Chan-Pin-Yin J, Tan H, Abramoff M, Twisk J, et al. The spatial relation of diabetic retinal neurodegeneration with diabetic retinopathy. PLoS One. 2020;15:e0231552.

11. Uğurlu N, Uzel AG, Şengün A, Yülek F, Özdas D, Tam AA, et al. Evaluation of the correlation between quantitative measurement of the foveal avascular zone and retinal vessel density and outer retinal disruptions in diabetic patients. Turk J Med Sci. 2019;49:1041-6.

12. AttaAllah HR, Mohamed AA, Ali MA. Macular vessels density in diabetic retinopathy: quantitative assessment using optical coherence tomography angiography. Int Ophthalmol. 2019;39:1845-59.

13. Farrah TE, Dhillon B, Keane PA, Webb DJ, Dhaun N. The eye, the kidney, and cardiovascular disease: old concepts, better tools, and new horizons. Kidney Int. 2020;98:323-42.

14. Wang W, He M, Gong X, Wang L, Meng J, Li Y, et al. Association of renal function with retinal vessel density in patients with Type 2 diabetes by using swept-source optical coherence tomography angiography. $\mathrm{Br} J$ Ophthalmol. 2020;104:1768-73. 